\title{
Qualitative and quantitative assessment of mites (Acari) in domiciliary dust in rural dwellings in the "Zona da Mata" region, Minas Gerais, Brazil
}

\author{
Aristeu José de Oliveira ${ }^{1} \&$ Erik Daemon ${ }^{2}$ \\ ${ }_{1}$ Rua Marechal Floriano Peixoto 606/101, Centro, 36015-440 Juiz de Fora, Minas Gerais, Brasil. \\ 2 Departmento de Zoologia, ICB, Universidade Federal de Juiz de Fora. Campus Universitário, 36033-330 Juiz de Fora, Minas \\ Gerais, Brasil.
}

\begin{abstract}
From July to September, 2000 (winter), and from January to March, 2001 (summer), 30 dust samples were collected for each season, from beds of rural dwellings located in farms in the geographical area named “Zona da Mata”, Minas Gerais, Brazil. After being sorted, the mites were identified and quantified. The prevalence of mites in the samples was $100 \% .891$ mites were found in winter $(22.97 \%)$, and 2988 in summer $\mathbf{( 7 7 . 0 3 \% ) . ~ I n ~ w i n t e r , ~ D e r m a t o p h a g o i d e s ~ p t e r o n y s s i n u s ~ ( T r o u e s s a r t , ~ 1 8 9 7 ) ~ w a s ~ t h e ~ m o s t ~ p r e v a l e n t ~ ( 5 5 . 0 0 \% ) , ~ f o l l o w e d ~ b y ~}$ Blomia tropicalis (Bronswijk, Cock \& Oshima, 1973) (27.06\%), Euroglyphus maynei (Cooreman, 1950) (8.85\%), and predator mites from Cheyletidae family (8.07\%). In summer, the most prevalent species was B. tropicalis (47.79\%), followed by D. pteronyssinus (43.38\%), Cheyletidae (6.87\%), and E. maynei $(1.28 \%)$. Few Dermatophagoides farinae (Hughes, 1961), Chortoglyphus arcuatus (Troupeau, 1879), and mites from Tarsonemidae and Cunaxidae families were found, the last two occurring only in summer. No mites from Acaridae family were found. The greatest number of immature forms found in summer suggested a greater breeding activity in this season. It was also noted that different building materials and varied cleaning routines may influence the population size of domiciliary dust mites.
\end{abstract}

KEY WORDS. Air humidity, allergens, allergy, beds, countryside, seasonal variations.

Several arthropods are found in domiciliary fauna, mites playing an important role due to their prevalence and their association to allergic disorders in specially sensitive subjects. Although mite species in domiciliary dust may vary according to the geographical location, as temperature and air relative humidity influence the occurrence and size of their populations, a fact confirmed by ArLian et al. (1982, 1992, 1999), a few species are representative and prevalent enough to be of importance (Blythe 1976). Pyroglyphidae, the most important family, is composed of 18 genera and 46 species, 28 of which have been found on birds or in their nests and five in stored food or on mammals, the 13 remaining ones being found in domiciliary dust (FAIN et al. 1990). According to HART (1995), three species are routinely present in dwellings all over the world: Dermatophagoides pteronyssinus (Trouessart, 1897), Dermatophagoides farinae (Hughes, 1961), and Euroglyphus maynei (Cooreman, 1950).

Blomia tropicalis (Bronswijk, Cock \& Oshima, 1973) (Glycyphagidae) has been playing an increasingly important role due to its high prevalence in tropical and sub-tropical regions. Suidasia pontificia (Oudemans, 1905), Tyrophagus putrescentiae (Schrank, 1781) and Aleuroglyphus ovatus (Troupeau, 1879) (Acaridae) also have an outsanding role in our acarofauna and in the pathophysiology of respiratory allergy, as was demonstrated in studies of skin sensitivity in allergic subjects (BAGGIO et al. 1989; Mori et al. 1992). Amaral (1968), in studies carried out in São Paulo, was the first to report mites in domiciliary dust in Brazil. Other authors surveyed mite populations and biology in domiciliary dust from large Brazilian towns such as São Paulo, Porto Alegre, Recife and Salvador (Jorge-Neto et al. 1984, Bernd et al. 1994, Sarinho et al. 1996, Serravalle \& Medeiros JúNIOR 1998). GaLṼ̃o \& GUITTON (1986) surveyed mite populations in the capitals of Brazilian states and Isle Fernando de Noronha, having even drawn a key to the identification of the main species found. No references regarding acarofauna in rural dwellings in Brazil were found. The aims of this study were to survey the acarofauna in the intradomiciliary ecosystem of rural dwellings in the Zona da Mata region of Minas Gerais, assess its seasonal variation (winter and summer), and seek a relationship between mite occurrence and different building materials and varied cleaning routines.

\section{MATERIAL AND METHODS}

Thirty samples of domiciliary dust were collected from randomly chosen rural dwellings in farms located in the mu- 
nicipalities of Coronel Pacheco (20 samples), Pedro Teixeira (5 samples), and Simão Pereira (5 samples), all in the Zona da Mata, Minas Gerais. The city of Juiz de Fora $\left(43^{\circ} 20^{\prime} 50^{\prime \prime} \mathrm{W}\right.$, $21^{\circ} 45^{\prime} 35^{\prime \prime} \mathrm{S}$ ) is the regional reference, and has a tropical or high altitude tropical climate, with dry winters with lower temperatures and humid summers with higher temperatures. Sampling happened from July to September, 2000 (winter) and from January to March, 2001 (summer), in the same houses, between $10: 00 \mathrm{~h}$ and $15: 00 \mathrm{~h}$, through aspiration of bed mattresses for two minutes, covering an area of $1 \mathrm{~m}^{2}$. An Electrolux HydroVAC $\mathrm{A}^{\circledR} 1300 \mathrm{~W}$, with a paper filter- containing device, designed to retain mites, connected to its end, was used. Temperature and air relative humidity were measured with a digital thermo-hygrometer (Fisher Pen-Type Thermo-Hygrometer ${ }^{\circledR}$ ). A field form including data about the region, house and mattress cleaning routine, roofing, wall covering material, and kind of ceiling and floor, was filled in. After sampling, the sample containing filter was sealed in a plastic bag, identified, and stored at $4^{\circ} \mathrm{C}$.

Mite sorting and recovery was based on Natuhara (1989). From each sample collected, 100mg of domiciliary dust were separated and put in a container with $50 \mathrm{ml}$ of $50^{\circ} \mathrm{GL}$ ethanol. After stirring for a minute, the content was passed consecutively through $1 \mathrm{~mm}$ and a $0.075 \mathrm{~mm}$ sieves. This procedure was repeated twice. The material retained in the $0.075 \mathrm{~mm}$ sieve was then dyed with methylene blue and, after a few minutes, rinsed with water, passed trough paper filter and examined through entomological microscopy. Mites, visualized in their natural color against the contrasting blue of the remaining field, were picked up with a fine needle. After collection, the mites were mounted on microscope slide using "Hoyer's medium" (FLecthMANN 1975) for subsequent counting and identification, using entomological and light microscopy. The keys developed by BronswiJK \& SinHA (1971), GaLVão \& GUITTON (1986) and Collof \& SpIexsma (1992) were used for identification.

As sampling took place in different geographical locations, Sorenson's Similarity Index (Ss) (PINTO-CoelHo 2000) was used to assess the degree of similarity among these different sites' acarofauna. Statistics consisted of descriptive analysis of data and non-parametric tests (Mann-Whitney and Chi Square). A level of 0.05 was considered significant.

\section{RESULTS}

All domiciliary dust samples were positive, mite prevalence being thus $100 \%$. In all, 3879 mites were present in the $6 \mathrm{~g}$ of dust. 891 mites were found in winter, representing a density of 297 mites/g of dust. Air relative humidity ranged from 32 to $72 \%$ (mean $52.53 \% \pm 10.59 \%$ ), with temperatures ranging from 18.8 to $32.2^{\circ} \mathrm{C}$ (mean $25.42^{\circ} \mathrm{C} \pm 3.31^{\circ} \mathrm{C}$ ). 2988 mites were found in summer, a density of 996 mites/g of dust. In this season, air relative humidity ranged from 62 to $88 \%$ (mean $76.93 \% \pm 6.64 \%$ ), with temperatures ranging from $24.4^{\circ} \mathrm{C}$ to $32.9^{\circ} \mathrm{C}$ (mean $29.08^{\circ} \mathrm{C} \pm 2.25^{\circ} \mathrm{C}$ ). Of the 3879 mites found in this study, 2889 were in the adult stage $(74.48 \%)$ and were identified, 261 were larvae (6.73\%), 497 nymphs (12.81\%), and $232(5.98 \%)$ were destroyed and not amenable to identification. Of the total 3879 mites, $22.96 \%$ were found in winter and $77.04 \%$ in summer. In 23 samples, the total number of mites collected in winter was lower than in summer; in six samples this figure was higher in winter than in summer, and in one sample it was similar in both seasons.
Table I shows the distribution of the identified mites according to their families. Species from the Pyroglyphidae family predominated, followed by Glycyphagidae, Cheyletidae, Tarsonemidae, Chortoglyphidae and Cunaxidae, the last three being less representative. There was a greater prevalence of Pyroglyphidae followed by Glycyphagidae in winter, while the situation was reversed in summer. No mites from the Acaridae family were found. It is noteworthy that $100 \%$ of Glycyphagidae mites belonged to $B$. tropicalis species. Among the identified species (Tab. II), D. pteronyssinus was the most prevalent, accounting for $46.52 \%$ of all mites, folowed by B. tropicalis, with $42.19 \%$. The figures show that there were approximately twice as many $D$. pteronyssinus mites as $B$. tropicalis ones in winter (429:211), while the numbers were similar $(915: 1008)$ in summer. E. maynei, on the other hand, presented a total prevalence of $3.32 \%$. In winter, out of 780 adult mites identified, 69 belonged to that species $(8.85 \%)$ and, in summer, out of 2109 adults identified, only $27(1.28 \%)$. The low prevalence of $D$. farinae was noteworthy: five mites in winter $(0.64 \%)$ and one in summer $(0.05 \%)$. The predator mites belonging to the Cheyletidae family presented very similar prevalence rates: $8.08 \%$ in winter and $6.88 \%$ in summer. This study found mites from the Cheyletidae family in 16 of the 30 samples in winter $(53.33 \%)$, and in 21 of the 30 samples in summer $(70.00 \%)$. Mites from the Tarsonemidae family were not found in winter. Of all adult mites identified, 10 were from that family $(0.5 \%)$. Another species with low prevalence was $C$. arcuatus, with only four mites in all adults identified $(0.14 \%)$. Two mites $(0,07 \%)$ from the Cunaxidae family, were found in one of the 30 samples collected in summer.

Table I. Distribution of adult mites identified by family in domiciliary dust samples from rural dwellings of the Zona da Mata region, Minas Gerais, Brazil, from July to September, 2000 (winter) and from January to March, 2001 (summer).

\begin{tabular}{|c|c|c|c|c|c|c|}
\hline \multirow{2}{*}{ Family } & \multicolumn{2}{|c|}{ Total of mites } & \multicolumn{2}{|c|}{ Winter } & \multicolumn{2}{|c|}{ Summer } \\
\hline & $n$ & $\%$ & $n$ & $\%$ & $\mathrm{n}$ & $\%$ \\
\hline Pyroglyphidae & 1446 & 50.05 & 503 & 64.49 & 940 & 44.71 \\
\hline Glycyphagidae & 1219 & 42.19 & 211 & 27.05 & 1008 & 47.80 \\
\hline Cheyletidae & 208 & 7.20 & 63 & 8.08 & 145 & 6.88 \\
\hline Tarsonemidae & 10 & 0.35 & 0 & 0.00 & 10 & 0.47 \\
\hline Chortoglyphidae & 4 & 0.14 & 3 & 0.38 & 1 & 0.05 \\
\hline Cunaxidae & 2 & 0.07 & 0 & 0.00 & 2 & 0.09 \\
\hline
\end{tabular}

Samples for this study were randomly collected in three distinct geographical regions: Coronel Pacheco (20 samples), Pedro Teixeira (5 samples), and Simão Pereira (5 samples). In order to assess the degree of similarity among the acarofauna of these three regions, taken in pairs, Sorenson's Similarity Index (PINTO-CoelHo 2000) was applied. The similarity was high: Ss $=0.73$ between Coronel Pacheco and Pedro Teixeira and between Pedro Teixeira and Simão Pereira, and Ss $=0.67$ between Coronel Pacheco and Simão Pereira. 
Table II. Absolute and relative (referring to the total number of species and families) numbers of mites identified in domiciliary dust samples from rural dwellings of the Zona da Mata region, Minas Gerais, Brazil, from July to September, 2000 (winter) anf from January to March, 2001 (summer).

\begin{tabular}{|c|c|c|c|c|c|c|}
\hline \multirow{2}{*}{ Species/Family } & \multicolumn{2}{|c|}{ Total $(\mathrm{N}=2889)$} & \multicolumn{2}{|c|}{ Winter $(N=780)$} & \multicolumn{2}{|c|}{ Summer $(\mathrm{N}=2109)$} \\
\hline & $\mathrm{n}$ & $\%$ & $\mathrm{n}$ & $\%$ & $\mathrm{n}$ & $\%$ \\
\hline Dermatophagoides pteronyssinus & 1344 & 46.52 & 429 & 55.00 & 915 & 43.38 \\
\hline Blomia tropicalis & 1219 & 42.19 & 211 & 27.06 & 1008 & 47.79 \\
\hline Euroglyphus maynei & 96 & 3.32 & 69 & 8.85 & 27 & 1.28 \\
\hline Dermatophagoide farinae & 6 & 0.20 & 5 & 0.64 & 1 & 0.05 \\
\hline Chortoglyphus arcuatus & 4 & 0.14 & 3 & 0.38 & 1 & 0.05 \\
\hline Cheyletidae & 208 & 7.20 & 63 & 8.08 & 145 & 6.88 \\
\hline Tarsonemidae & 10 & 0.35 & 0 & 0.00 & 10 & 0.47 \\
\hline Cunaxidae & 2 & 0.07 & 0 & 0.00 & 2 & 0.09 \\
\hline
\end{tabular}

The methods mentioned a field form which, among its aims, included the putative effect of the type of house and building materials, as well as the cleaning routine of the houses and mattresses on the mite populations. It was noticed that in winter, houses with wooden roofs and floors presented a greater number of mites. In summer, although the number of mites was far greater than in winter, houses with the practice of sunbathing mattresses had fewer mites.

\section{DISCUSSION}

The greater number of mites in summer was in accordance with literature data that point to a significant increase in mite population in domiciliary dust during this season. The record of a large number of young stages (larvae and nymphs) in this season points to an increased breeding activity (Tab. III). The absence of mites from the Acaridae family, frequently found in dust samples collected in several Brazilian cities (JORGENeto et al. 1984, Bernd et al. 1994, Serravalle \& Medeiros Júnior 1998), may have been occasional. Ezequiel et al. (2001) found $1.6 \%$ of mites from that family in the city of Juiz de Fora, situated in Zona da Mata, Minas Gerais. As for Glycyphagidae family, the finding of mites only from $B$. tropicalis species confirms results found by other authors, who found low occurrence of species from the other genera of this family in Brazil (BERND et al. 1994; Serravale \& Medeiros Júnior 1998). The greater prevalence of $D$. pteronyssinus and $B$. tropicalis species was to be expected. BAGGIO et al. (1989) stated that there was a prevalence of these species in South America, with alternation depending on climatic conditions (air relative humidity and temperature), nutritional factors and on the environment where sampling occurred. The predominance of $D$. pteronyssinus in winter suggests a greater resistance to low levels of air relative humidity, in comparison with $B$. tropicalis. This study showed a greater prevalence of $E$. maynei in winter. This species has water demands similar to those suggested for $D$. pteronyssinus. According to HART (1995), it is the second most important species on the European coastline, rarely occurring in the United States, Russia, and in tropical countries like Brazil. Information about its biology is little, owing to the difficulty of growing colonies in the laboratory. The explanation for the predominance of $D$.
Table III. Ocurrence of mite immature stages in domiciliary dust samples from rural dwellings of the Zona da Mata region, Minas Gerais, Brazil, from July to September, 2000 (winter) and from January to Mach, 2001 (summer).

\begin{tabular}{ccccccc}
\hline \multirow{2}{*}{ Stage } & \multicolumn{2}{c}{ Winter $(\mathrm{N}=891)$} & & \multicolumn{2}{c}{ Summer $(\mathrm{N}=2988)$} \\
\cline { 2 - 3 } \cline { 5 - 6 } & $\mathrm{n}$ & $\%$ & & $\mathrm{n}$ & $\%$ \\
\hline Larvae & 12 & 1.35 & & 249 & 8.33 \\
Nymph & 77 & 8.64 & & 420 & 14.05 \\
\hline
\end{tabular}

pteronyssinus over E. maynei is thought to be linked to their different reproduction rates (HART 1995). Further studies about E. maynei are necessary to understand the rationale underlying the greater prevalence in winter found in this study. $D$. farinae species was noticed to be of low prevalence. According to ArLian (1989) this species is more resistant to falls in air relative humidity, thus predominating in drier regions, while in high humidity regions $D$. pteronyssinus predominates. The geographical features of the region studied, habitually humid, anticipated a predominance of $D$. pteronyssinus over $D$. farinae, a fact demonstrated by this study findings. The biological and antigenic importance of mites from the Cheyletidae family await more specific studies. BERND et al. (1994), in a study carried out in Porto Alegre, found Cheyletus malaccensis "in a reasonable number of dwellings", coming fourth in prevalence, after $D$. pteronyssinus, B. tropicalis, and T. putrescentiae. SERRAVALLE \& MedeIros JúnIor (1998), in Salvador, Bahia, reported Cheyletus $s p$. in $50 \%$ of the samples studied, coming second only to $D$. pteronyssinus. These authors underscored the importance of studying these mites' ability to provoke allergic reactions, due to their high prevalence. Amвrózio et al. (1989) found $41.1 \%$ of positive skin tests for $C$. malaccensis carried out in allergic patients in the city of São Paulo. Lozano (1979) in Caracas, Venezuela, found $55 \%$ of positive intradermal skin tests for Cheyletus sp. in asthmatic patients. As their Cheyletidae mites cultures were fed with Dermatophagoides sp., he suggested that the results might be influenced by this fact. Assuming that any mite may be potentially allergenic, as long as there is a 
concurrence of predisposing factors (a sensitive subject, massive mite populations, and sufficiently long exposure), the Cheyletidae family may be important in the causation of allergic disorders, its inclusion in allergic tests preceding immunotherapy being warranted. Mites from the Tarsonemidae family are known in international literature as "mites from humidity", this factor being thought of as the controller of population size, a fact that might explain its presence only in samples collected in summer. In a study carried out monthly in Porto Alegre, BERND et al. (1994) found a total prevalence of $0.46 \%$ of Tarsonemus sp. Another species with low prevalence was $C$. arcuatus. This is a little studied species whose role as an allergen remains elusive. Literature data show contradictory results as refers to its prevalence. GALṼ̃o \& GUITTON (1986), studying mites in domiciliary dust from Brazilian capitals and Isle Fernando de Noronha, found that species in six of the twenty-seven capitals studied (São Luís, Aracaju, Salvador, Belo Horizonte, Rio de Janeiro and Florianópolis). A previous study, carried out in the city of São Paulo by Jorge-NeTo et al. (1984), showed a greater prevalence for C. arcuatus (18.75\%) than for D. pteronyssinus (9.93\%), the former being second only to B. tropicalis (55.74\%). Some diferences among the studies, not only as refers to $C$. arcuatus, but also to other mite species in domiciliary dust, can possibly be accounted for by the different methods applied; the kind of dwelling, the sites of domiciliary sampling, climatic factors, and species competition must also be taken into account. The finding of mites from the Cunaxidae family in one of the 30 samples collected in summer may be attributed to serendipity, as they prey on other plant and soil living species. The results from Sorensen's Similarity Index, which showed a similarity around $70 \%$ for species and families in the three regions studied, suggested that there was not enough variation to account for expressive differences among the acarofauna.

The greater number of mites in houses with wooden roofs and floors may be because this material keeps the environment warmer and wetter, contributing, somehow, to adequate intradomiciliary levels of temperature and humidity. Craks and crevices in the roofs and floors are also good shelters for mites. Houses with the practice of sunbathing mattresses in summer had fewer mites, a fact which may be attributed to the heat and consequent dehydration, with its negative influence on mite populations.

Qualitative assessment of mites in the intradomiciliary ecosystem of rural dwellings of Zona da Mata, Minas Gerais, did not show significant differences between rural and urban acarofauna. Data from studies to assess the frequency of sensitization of rural populations to different mite species might be useful when considering immunotherapy against allergic symptoms in this group. Quantitatively, this study showed that air relative humidity is undoubtedly the most relevant factor, with a direct influence on mite population size. Due to its high prevalence, $B$. tropicalis was noticed to have become as important an allergen as $D$. pteronyssinus. This is in accordance with what has been seen in daily practice, where an increasing number of allergic patients show positivity to $B$. tropicalis in the skin prick test, regardless of positivity to $D$. pteronyssinus.

\section{REFERENCES}

Amaral, V. 1968. Sobre a ocorrência do ácaro Dermatophagoides pteronyssinus Trouessart, 1897) no Brasil (Psoroptidae,
Sarcoptiformes). Revista de Medicina Veterinária, São Paulo, 3: 296-300.

Ambrózio, L.C.; D. Baggio; J.C. Mori; M.F.M. Fernandes; M.T. KaSE \& J.F. Mello. 1989. Suidasia pontificia: alergizante de vias respiratórias? Revista Brasileira de Alergia e Imunopatologia, São Paulo, 12: 15.

ArLiAn, L.G. 1989. Biology and ecology of house dust mites. Immunology and Allergy Clinics of North America, Tucson, 9 (2): 339-356.

Arlian, L.G.; D. Bernstein; I.L. Bernstein; S. Friedman; A.Grant; P. Liberman; M. Lopez; T. Platts-Mills \& M. Schatz. 1992. Prevalence of dust mites in the homes of people with asthma living in eight different geographic areas of the United States.The Journal of Allergy and Clinical Immunology, Saint Louis, 90 (3Pt 1): 292-300.

Arlian, L.G.; I.L. Bernstein \& J.S. Gallagher. 1982. The prevalence of house dust mites, Dermatophagoides spp., and associated environmental conditions in homes in Ohio. The Journal of Allergy and Clinical Immunology, Saint Louis, 69: 527.

Arlian, L.G.; J.S. Neal \& D.L. Vyszenski-Moher. 1999. Fluctuating hydrating and dehydrating relative humidites effects on the life cycle of Dermatophagoides farinae (Acari - Pyroglyphidae). Journal of Medical Entomology, Lanham, 36 (4): 457-461.

Baggio, D.; L.C. Ambrózio \& M.A. Ambrózio. 1989. Ácaros ambientais e manifestações alérgicas. Revista Brasileira de Alergia e Imunopatologia, São Paulo, 12 (2): 56-68.

Bernd, L.A.G.; D. Baggio; A.B. Becker \& L.C. Ambrózio. 1994. Identificação e estudo da atividade sensibilizante de ácaros domésticos em Porto Alegre (RS). Revista Brasileira de Alergia e Imunopatologia, São Paulo, 17 (1): 23-33.

BlyTHE, M.E. 1976. Some aspects of the ecological study of the house dust mites. British Journal of Diseases of the Chest, London, 70: 3-31.

BRonswiJK J.E.M.H. van \& R.N. SinHA. 1971. Pyropgyphid mites (Acari) and house dust allergy. Journal of Allergy, Saint Louis, 47 (1): 31-51.

Collof, M.J. \& F.Th.M. Siteksma. 1992. Pictorial keys for the identification of domestic mites. Clinical and Experimental Allergy, London, 22: 823- 830.

Ezequiel, O.S.; G.S. Gazêta; M. Amorim \& N.M. Serra-Freire. 2001. Evaluation of the acarofauna of the domiciliary ecosystem in Juiz de Fora, State of Minas Gerais, Brazil. Memórias do Instituto Oswaldo Cruz, Rio de Janeiro, 96 (7): 911-916.

FaIN, A.; B. Guérin \& B.J. HART. 1990. Mites and Allegic Disease. Varennes en Argonne, France, Allerbio, 190p.

Fletchmann, C.H.W. 1975. Elementos de Acarologia. São Paulo, Nobel, 344p.

Galvão, A.B. \& N. GuitTon. 1986. Ácaros em poeira domiciliar das capitais brasileiras e Ilha Fernando de Noronha. Memórias do Instituto Oswaldo Cruz, Rio de Janeiro, 8 (4): 417-430.

HART, B.J. 1995. The Biology of Allergenic Domestic Mites. Clinical Reviews in Allergy and Immunology, Totowa, 13: 115133.

Jorge-Neto, J.; J. Croce \& D. Baggio. 1984. Ácaros da poeira domiciliar da cidade de São Paulo - SP. Revista Brasileira de Alergia e Imunopatologia, São Paulo, 2 (3): 140.

LozANO, A. P. 1979. Environmental control in asthmatic homes. The role of cheylatus mites. Preliminary report. Allergologia

Revista Brasileira de Zoologia 20 (4): 675-679, dezembro 2003 
et Immunopathologia, Barcelona, 7: 303-306.

Mori, J.C.; M.T. Kase; M. Chertman; W.T. Aun; J.F. Mello, D. BAGGIO \& L.C. AMBRÓZIO. 1992. Alleuroglyphus ovatus: importância antigênica. Revista Brasileira de Alergia e Imunopatologia, São Paulo, 15: 206.

NATUHARA, Y. 1989. New wet sieving method for isolating house dust mites. Japanese Journal of Sanitary Zoology, Tokyo, 40: 333-336.

Pinto-Coelho, R.M. 2000. Fundamentos em Ecologia. Porto
Alegre, Artes Médicas, 22p.

Sarinho, E.; E. FernándeZ-Caldas; R. Just \& D. Solé. 1996. Ácaros da poeira domiciliar em residências de crianças asmáticas e controles da cidade de Recife, Pernambuco.

Revista Brasileira de Alergia e Imunopatologia, São Paulo, 19 (5): 228-230.

Serravalle, K \& M. Medeiros Júnior. 1998. Ácaros da poeira domiciliar na cidade de Salvador- BA. Revista Brasileira de Alergia e Imunopatologia, São Paulo, 22 (1): 19-24.

Received in 06.V.2003; accepted in 08.XI.2003. 